\title{
A Draft Genome Sequence of Pseudomonas syringae pv. tomatoT1 Reveals a Type III Effector Repertoire Significantly Divergent from That of Pseudomonas syringae pv. tomato DC3000
}

\author{
Nalvo F. Almeida, ${ }^{1,7}$ Shuangchun Yan, ${ }^{2}$ Magdalen Lindeberg, ${ }^{3}$ David J. Studholme, ${ }^{4}$ David J. Schneider, ${ }^{5}$ \\ Bradford Condon, ${ }^{3}$ Haijie Liu, ${ }^{2}$ Carlos J. Viana, ${ }^{7}$ Andrew Warren, ${ }^{1}$ Clive Evans, ${ }^{1}$ Eric Kemen, ${ }^{4}$ \\ Dan MacLean, ${ }^{4}$ Aurelie Angot, ${ }^{3,6}$ Gregory B. Martin, ${ }^{3,6}{ }^{6}$ Jonathan D. Jones, ${ }^{4}$ Alan Collmer, ${ }^{3}$ \\ Joao C. Setubal, ${ }^{1,8}$ and Boris A. Vinatzer ${ }^{2}$ \\ ${ }^{1}$ Virginia Bioinformatics Institute, Virginia Tech, Blacksburg, VA 24061, U.S.A.; ${ }^{2}$ Department of Plant Pathology, Physiology, \\ and Weed Science, Virginia Tech, Latham Hall, Ag Quad Lane, Blacksburg, VA 24061, U.S.A.; ${ }^{3}$ Department of Plant \\ Pathology and Plant-Microbe Biology, Cornell University, Ithaca, NY 14853, U.S.A. ${ }^{4}$ Sainsbury Laboratory, Norwich \\ NR4 7UH, U.K.; ${ }^{5}$ U. S. Department of Agriculture Agricultural Research Service, Ithaca, NY 14853, U.S.A.; ${ }^{6}$ Boyce \\ Thompson Institute for Plant Research, Ithaca, NY 14853, U.S.A.; ${ }^{7}$ Department of Computing and Statistics, Federal \\ University of Mato Grosso do Sul, Brazil; ${ }^{8}$ Department of Computer Science, Virginia Tech, Blacksburg, VA 24061, U.S.A. \\ Submitted 11 July 2008. Accepted 10 September 2008.
}

Diverse gene products including phytotoxins, pathogen-associated molecular patterns, and type III secreted effectors influence interactions between Pseudomonas syringae strains and plants, with additional yet uncharacterized factors likely contributing as well. Of particular interest are those interactions governing pathogen-host specificity. Comparative genomics of closely related pathogens with different host specificity represents an excellent approach for identification of genes contributing to host-range determination. A draft genome sequence of Pseudomonas syringae pv. tomato T1, which is pathogenic on tomato but nonpathogenic on Arabidopsis thaliana, was obtained for this purpose and compared with the genome of the closely related $A$. thaliana and tomato model pathogen $P$. syringae pv. tomato DC3000. Although the overall genetic content of each of the two genomes appears to be highly similar, the repertoire of effectors was found to diverge significantly. Several $P$. syringae pv. tomato $\mathrm{T} 1$ effectors absent from strain DC3000 were confirmed to be translocated into plants, with the well-studied effector AvrRpt2 representing a likely candidate for host-range determination. However, the presence of avrRpt 2 was not found sufficient to explain $A$. thaliana resistance to $P$. syringae pv. tomato $\mathrm{T} 1$, suggesting that other effectors and possibly type III secretion systemindependent factors also play a role in this interaction.

Additional keywords: effector-triggered immunity, nonhost resistance, pyrosequencing, Solexa sequencing.

Nalvo F. Almeida, Shuangchun Yan, and Magdalen Lindeberg contributed equally to this work.

Corresponding author: Boris A. Vinatzer; E-mail: vinatzer@vt.edu

Nucleotide sequence data has been deposited as a Whole Genome Shotgun (WGS) project in the DDBJ/EMBL/GenBank database under project accession ABSM00000000. The version described in this paper is the first version, ABSM01000000.
Many closely related plant pathogens, though adapted to fundamentally similar plant-associated niches, exhibit striking differences in the species and cultivars that they can infect. Host ranges of plant pathogens are governed by a complex network of interactions between plant defense mechanisms and pathogen gene products, with current models of plant defense emphasizing the roles of pathogen (or microbe) associated molecular pattern (PAMP)-triggered immunity (PTI) and effector-triggered immunity (ETI) (Jones and Dangl 2006).

Also referred to as basal resistance, PTI bears significant resemblance to the basal immunity exhibited by animals against various pathogens (Angot et al. 2007; Bhavsar et al. 2007; Zipfel 2008). PTI is typically triggered when the plant in question detects conserved elements of the microbial structure, such as flagellin (Felix et al. 1999), elongation factor Tu (Kunze et al. 2004), or lipopolysaccharides (Newman et al. 2002). Detection gives rise to a variety of defense-related phenotypes, including callose formation and upregulation of defense-related proteins, ultimately resulting in hostrange restriction for a wide variety of microbes (Ham et al. 2007).

In contrast to the broad spectrum immunity conferred by recognition of the highly conserved PAMPs, ETI, also known as "gene-for-gene" resistance, involves detection of the more variable type III-secreted effector (T3E) proteins by plant resistance $(R)$ gene products (Chisholm et al. 2006). Detection of effectors can occur directly or indirectly via the plant's detection of alterations brought about by effector actions and frequently results in the induction of programmed cell death (PCD) (Dangl and Jones 2001). The fact that individual effectors are generally more dispensable than PAMPs coupled with heavy selective pressure on the pathogen and host to alternately evade and achieve detection can lead to extensive variation in the repertoires of effectors and $R$ genes among otherwise similar pathogens and hosts (Rohmer et al. 2004; Rose et al. 2007). Though ETI has been generally regarded as the basis for "host resistance" exhibited by individual plant cultivars and ecotypes to pathogen pathovars and 
races, evidence is accumulating that ETI can also play a critical role in "nonhost resistance" exhibited by all cultivars and ecotypes of a plant species against all strains of a pathogen. For example, HopQ1-1 was recently shown to be the determining factor in interfering with pathogenicity of $P$. syringae pv. tomato DC3000 on Nicotiana benthamiana (Wei et al. 2007), and recognition of the effectors AvrPtol (AvrPto) and HopAB2 (AvrPtoB) by the corresponding $R$ genes appears to exclude tomato from the host range of several $P$. syringae strains (Lin and Martin 2007).

For many nonhost plant-pathogen interactions, the ultimate outcome is shaped by the interplay of multiple defense pathways and gene products. For example, resistance of Arabidopsis thaliana to the fungal wheat pathogen Blumeria graminis appears to involve PTI and ETI. During a prehaustorial phase, formation of papillae and callose layers typical of PTI is observed. During the posthaustorial phase, an induction of the hypersensitive response (HR) and consequent PCD typical of ETI is observed (Lipka et al. 2005).

Among bacterial pathogens, the outcomes of nonhost plant interactions may similarly involve diverse pathways, with T3E proteins involved at many levels. In fact, in addition to limiting host range through ETI, effectors also have the capacity to extend host range by suppressing defense pathways, including those implicated in PTI and ETI. In DC3000, several effectors as well as the toxin coronatine confer the ability to suppress induction of the PAMP-induced A. thaliana NHOl gene implicated in nonhost resistance ( $\mathrm{Li}$ et al. 2005). P. syringae pv. phaseolicola 3121, which lacks coronatine and most of these effectors, is unable to suppress $\mathrm{NHOl}$ expression, likely contributing to its inability to cause disease on A. thaliana. Further evidence for the complexity of $A$. thaliana resistance to strain 3121 was uncovered by Ham and colleagues (2007), who found that strain 3121 elicits several parallel defense pathways in A. thaliana, with one of them being suppressed by the DC3000 effector HopM1.

To date, the genomes of three Pseudomonas syringae strains have been sequenced (Buell et al. 2003; Feil et al. 2005; Joardar et al. 2005) with bioinformatic analyses leading to the identification of over $40 \mathrm{~T} 3 \mathrm{E}$ (Lindeberg et al. 2008). Of these strains, the tomato isolate DC3000 has been most extensively studied as a model pathogen of $A$. thaliana and tomato. Multilocus sequence typing (MLST) (Maiden et al. 1998) has revealed that DC3000 belongs to a group of $P$. syringae isolates found on members of the Solanaceae and Brassicaceae families that is characterized by the ability to cause disease on both $A$. thaliana and tomato (Yan et al. 2008). Other isolates, though closely related to DC3000, have been found exclusively on tomato and cause disease only on tomato but not on A. thaliana (Yan et al. 2008). The isolate $\mathrm{T} 1$, whose inability to cause disease on $A$. thaliana was first described by Whalen and colleagues (Whalen et al. 1991), is a representative of this latter group of typical $P$. syringae pv. tomato strains.

To investigate the genetic basis of T1's inability to cause disease on A. thaliana, a deep-coverage draft genome sequence of T1 was obtained using two high-throughput DNA sequencing technologies, pyrosequencing (Margulies et al. 2005), and Solexa sequencing (Bentley 2006). The draft genome sequence was annotated and analyzed for the presence of conserved and potentially novel T3E, for the purpose of identifying genetic differences that account for the differing abilities of DC3000 and T1 to infect $A$. thaliana. Although the two genomes were found to align for most of their length, their effector repertoires were found to be highly divergent. As a first step in dissecting A. thaliana resistance response to $\mathrm{T} 1$, the role of ETI in this response was investigated.

\section{RESULTS}

\section{T1 is a nonpathogen of $A$. thaliana ecotypes and} causes a HR.

Previously reported comparisons of disease symptoms and bacterial growth between $A$. thaliana and tomato strain DC3000, the typical $P$. syringae pv. tomato isolate T1, and other $P$. syringae isolates closely related to $\mathrm{T} 1$ revealed significant differences in host range. Specifically, the T1 population size on the A. thaliana ecotype 'Columbia' was shown to be approximately $4 \log$ lower than that of DC3000 at 3 days postinfection and, in contrast to DC3000, T1 did not cause any disease symptoms (Yan et al. 2008). To evaluate whether this inability to multiply and to cause disease on A. thaliana is ecotype-specific or more widespread, comparisons of growth and symptom production were extended to three additional $A$. thaliana ecotypes and a type III secretion system (T3SS)-deficient derivative of DC3000 missing the $h r c C$ gene (DC3000 CUCPB5112 [Penaloza-Vazquez et al. 2000]) was included as a control. As shown in Figure 1, T1 only grows to a population size equivalent to the T3SS-deficient DC3000 strain on all four $A$. thaliana ecotypes and does not cause any disease symptoms. Similar results were obtained with additional $P$. syringae pv. tomato isolates that are very closely related to T1, based on MLST (Yan et al. 2008), and additional A. thaliana ecotypes (data not shown). Therefore, A. thaliana resistance to T1-like isolates is not limited to a single ecotype-strain combination, suggesting that $A$. thaliana might be generally resistant to typical $P$. syringae pv. tomato strains.

While plant and bacterial factors contributing to A. thaliana resistance to $\mathrm{T} 1$ await characterization, infection of ecotype 'Columbia' with a high dose of T1 induces a HR, suggesting that ETI may contribute to the resistance exhibited by $A$. thaliana to the T1-like isolates (Fig. 1C). This is in agreement with the earlier observation (Whalen et al. 1991) that cosmids containing T1 genome fragments when expressed in DC3000 reduced virulence on $A$. thaliana.

\section{T1 draft genome sequence obtained using Solexa sequencing and 454 pyrosequencing and compared with the DC3000 genome.}

To initiate identification of the genetic bases for the differing virulence of T1 and DC3000 on A. thaliana, a draft genome sequence of $P$. syringae pv. tomato T1 was obtained using 454 pyrosequencing (Margulies et al. 2005) and Solexa sequencing (Bentley 2006). Reads were assembled separately into draft genome sequences. Characteristics of the two drafts are compared in Table 1. Based on the total contig length of the two draft genomes, the T1 genome was sequenced to a 20 -fold coverage using 454 pyrosequencing and to a 94-fold coverage with Solexa sequencing. It is obvious that, although the Solexa genome coverage was more than four times greater than that of the 454 genome sequence, the longer pyrosequencing reads allowed a much more extensive assembly. To compare the quality of the two draft genome sequences, the two genomes were aligned and their average DNA identity was determined. The two drafts were found to be over $99.998 \%$ identical (1 difference every 100,000 bp) and are, thus, both of excellent quality. Moreover, all Solexa genome sequences were contained in the 454 genome sequence. Therefore, most of the subsequent analyses were conducted using the 454 draft genome sequence.

Given that the T1 454 draft genome sequence consists of 134 contigs, there are at least 134 gaps in the genome sequence. Most contig ends consist of repeated sequences, which is the reason why further assembly was not possible with current data. However, given the estimated genome coverage, we be- 
lieve that the vast majority of the critical virulence genes, including effectors, are identifiable from the current draft.

\section{Alignment of the T1 genome}

with the three sequenced $P$. syringae genomes

To investigate differences between $\mathrm{T} 1$ and the other sequenced $P$. syringae strains, the T1 draft genome was aligned

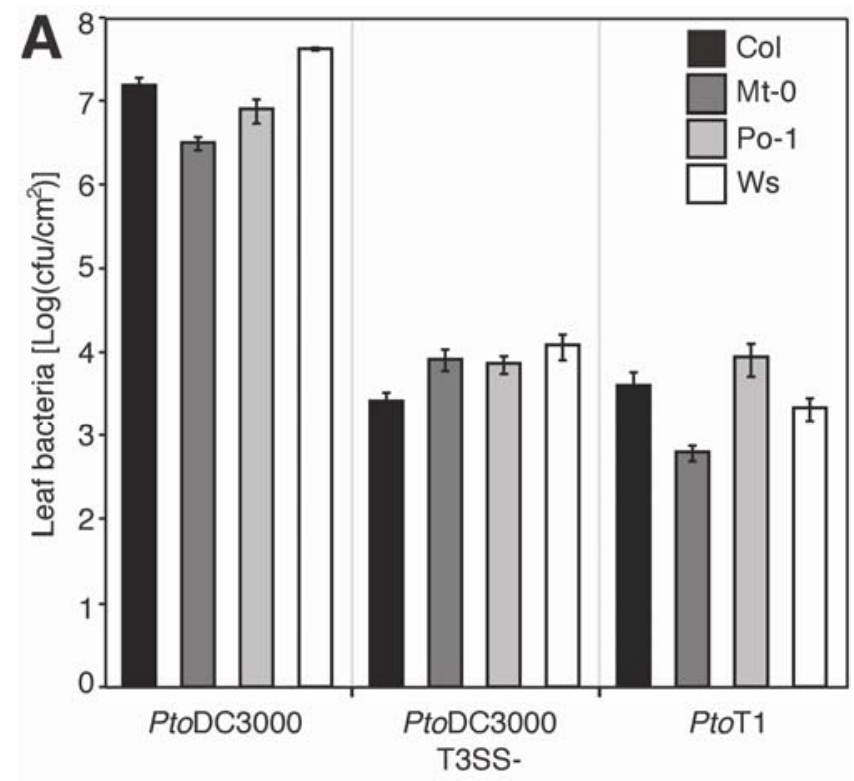

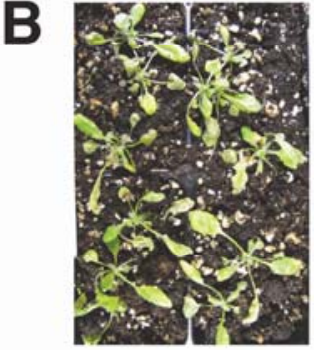

PtoDC3000

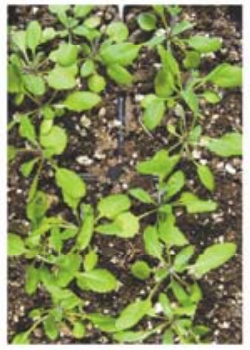

PtoDC3000 T3SS-

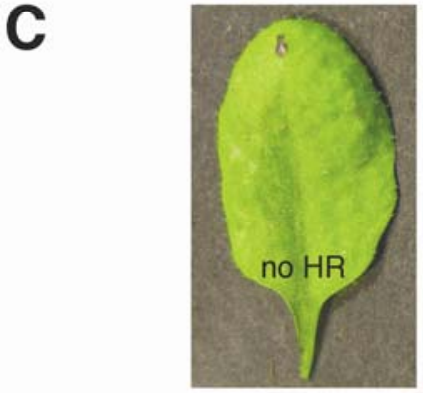

PtoDC3000

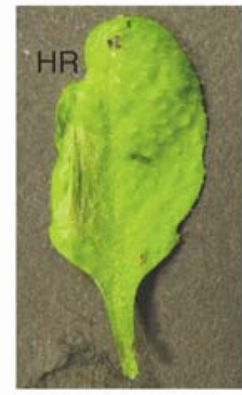

PtoT1

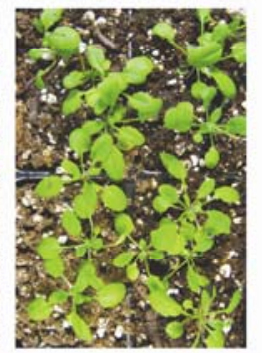

PtoT1

Fig. 1. Comparison of in planta growth and symptoms of the Arabidopsis thaliana and tomato pathogen Pseudomonas syringae pv. tomato DC3000, a type III secretion system-deficient mutant of DC3000 (DC3000 T3SS-), and the tomato pathogen $P$. syringae pv. tomato T1. A, Bacteria were sprayed onto A. thaliana ecotypes Columbia (Col-0), Mt-0, Po-1, and WS at an optical density at $600 \mathrm{~nm}\left(\mathrm{OD}_{600}\right)$ of 0.1 . At 3 days postinfection, $\mathrm{CFU}$ per square centimeter were determined. While population sizes of DC3000 were significantly larger than those of DC3000 T3SS- and T1 on all ecotypes $(P<0.0001)$, sizes of DC3000 T3SS- and T1 were not significantly different from each other on any of the ecotypes, based on Student's $t$-test $(P>0.1)$. B, A. thaliana $\mathrm{Col}-0$ plants were photographed a week postinfection. $\mathbf{C}$, Bacteria were infiltrated into leaves of A. thaliana Col-0 at an $\mathrm{OD}_{600}$ of 0.3 , and pictures were taken after $16 \mathrm{~h}$. with the closed genomes of DC3000 (Buell et al. 2003), strain 1448A (Joardar et al. 2005), and P. syringae pv. syringae B728a (Feil et al. 2005).

The T1 genome was first compared with the DC3000 genome using the latter as reference. Figure 2 shows alignments of the DC3000 chromosome and its two plasmids pDC3000A and pDC3000B (panels $\mathrm{A}, \mathrm{B}$, and $\mathrm{C}$, respectively) with both the 454 and the Solexa T1 draft genome sequences. It is evident from these figures that the DC3000 and the T1 genomes align over most of their length. Moreover, the alignments with the 454 and the Solexa T1 drafts are nearly identical, confirming the high quality of both genome sequences. As expected, alignment of the T1 draft genome sequence with the completely assembled B728a and 1448A genome sequences revealed significant divergence relative to the alignment of the two pathovar tomato strains. While 5,618,731 nt of DNA align between T1 and DC3000, only 4,547,158 nt of T1 align with the B728a genome and 4,689,063 nt align with the 1448A genome.

\section{Comparison of protein complements}

between the four $P$. syringae genomes.

In order to identify the repertoire of putative virulence genes in the $\mathrm{T} 1$ genome and to reveal differences between the DC3000 and T1 genomes that underlie differences in host range, an annotation of the $\mathrm{T} 1$ draft genome was generated. The annotation can be accessed at the DDBJ/EMBL/GenBank database as part of WGS project ABSM00000000 (version ABSM01000000). A total of 5,733 putative genes were predicted in this preliminary annotation, of which 3,987 (69\%) are similar to genes that encode proteins with known function in other bacterial genomes, $729(13 \%)$ are similar to genes that encode proteins with unknown function in other genomes ("conserved hypothetical proteins"), and 1,047 (18\%) putative genes are unique to T1 ("hypothetical proteins"). However, it should be noted that estimates of the numbers of repeated elements such as mobile genetic elements are less reliable owing to the unclosed nature of the genome.

The predicted proteins from T1 were compared with those of the other sequenced $P$. syringae genomes. A Venn diagram illustrating the number of predicted proteins shared between and unique to $\mathrm{T} 1$ and DC3000 relative to the B728a and 1448A protein repertoires is shown in Figure 3. In summary, 4,271 proteins are shared between all four genomes and thus represent conserved housekeeping gene products and virulence gene products most likely underlying fundamental adaptations to the plant-associated niche. A total of 471 proteins are only shared between DC3000 and T1 and are absent from B728a and 1448A and may include proteins with roles in pathogenicity on the shared host tomato. A total of 757 proteins are unique to $\mathrm{T} 1$. Of these, 511 are hypothetical proteins, 79 proteins can be classified as mobile genetic elements (transposons, insertion sequences, bacteriophage components, and other genes with predicted function in DNA replication), and 167 are proteins with other predicted functions. This latter category

Table 1. Comparison of the Pseudomonas syringae pv. tomato T1 draft genome sequences obtained by 454 pyrosequencing and Solexa sequencing

\begin{tabular}{lrr}
\hline Sequence characteristics & \multicolumn{1}{c}{$\mathbf{4 5 4}$} & \multicolumn{1}{c}{ Solexa } \\
\hline Number of reads & 519,729 & $15,723,622$ \\
Mean length of reads (nt) & 241 & 36 \\
Total length of reads (nt) & $125,281,22$ & $566,050,392$ \\
Number of assembled contigs & 134 & 3,825 \\
Mean length of contigs (nt) & 45,878 & 1,570 \\
Length of longest contig (nt) & 335,36 & 16,815 \\
Total length of contigs (nt) & $6,147,659$ & $6,005,250$ \\
Calculated genome coverage & 20.4 & 94 \\
\hline
\end{tabular}



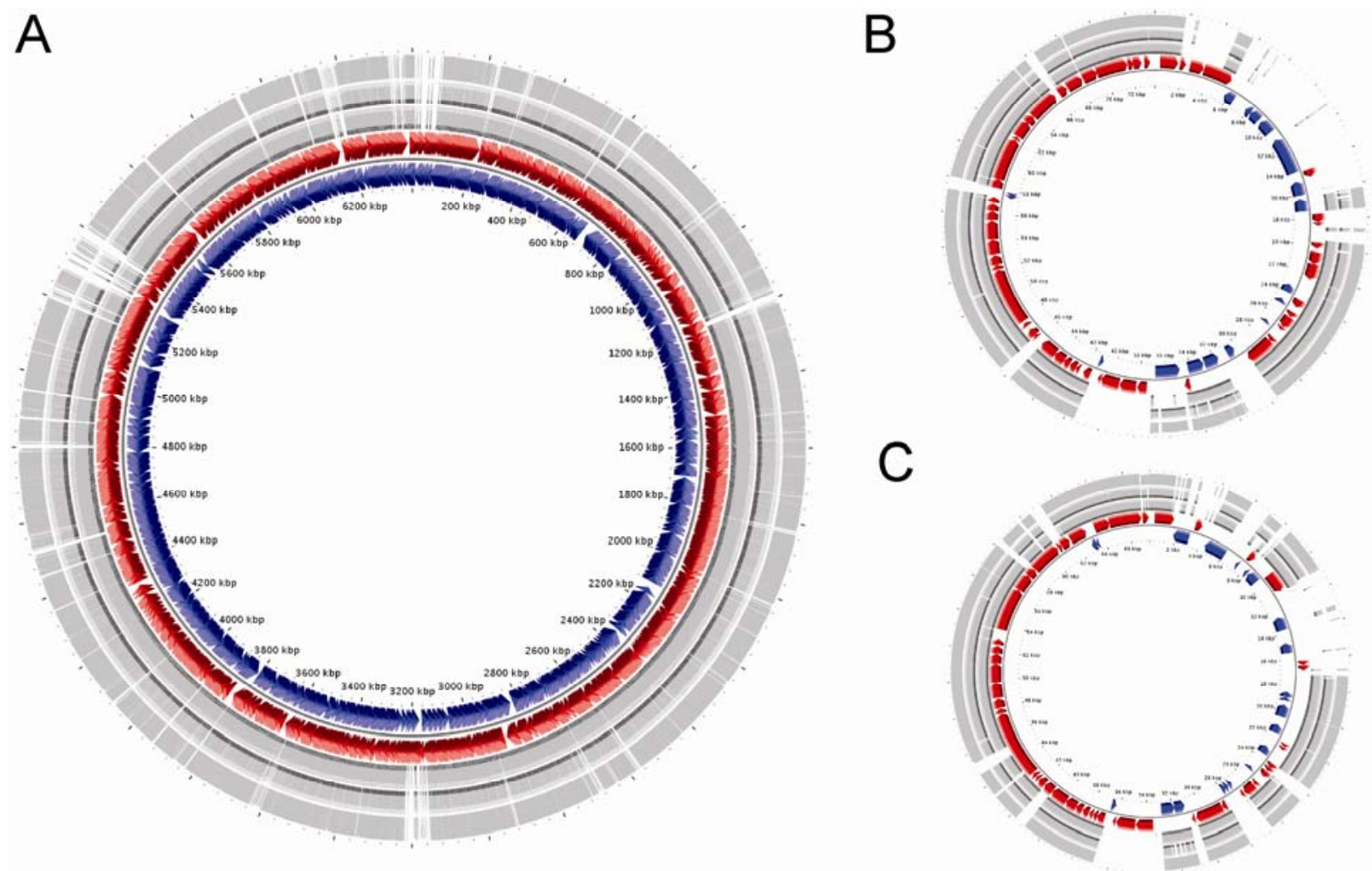

Fig. 2. Pairwise alignments between the Pseudomonas syringae pv. tomato T1 454 and Solexa draft genome sequences and the P. syringae pv. tomato DC3000 genome. A, Alignment of the T1 draft genome sequences with the DC3000 chromosome using the latter as reference. B and $\mathbf{C}$, Alignment of the T1 draft genome sequences with the DC3000 plasmids pDC3000A and pDC3000B, respectively. Genes in the reference genome are in blue and red. Plotted Going outwards in each panel as follows: alignment with T1 Solexa contigs, alignment with T1 454 contigs, and single nucleotide polymorphism based on the Solexa consensus sequence. Closeups of local alignments corresponding to the type III-secreted effectors can be viewed on the PtoT1 genome website.

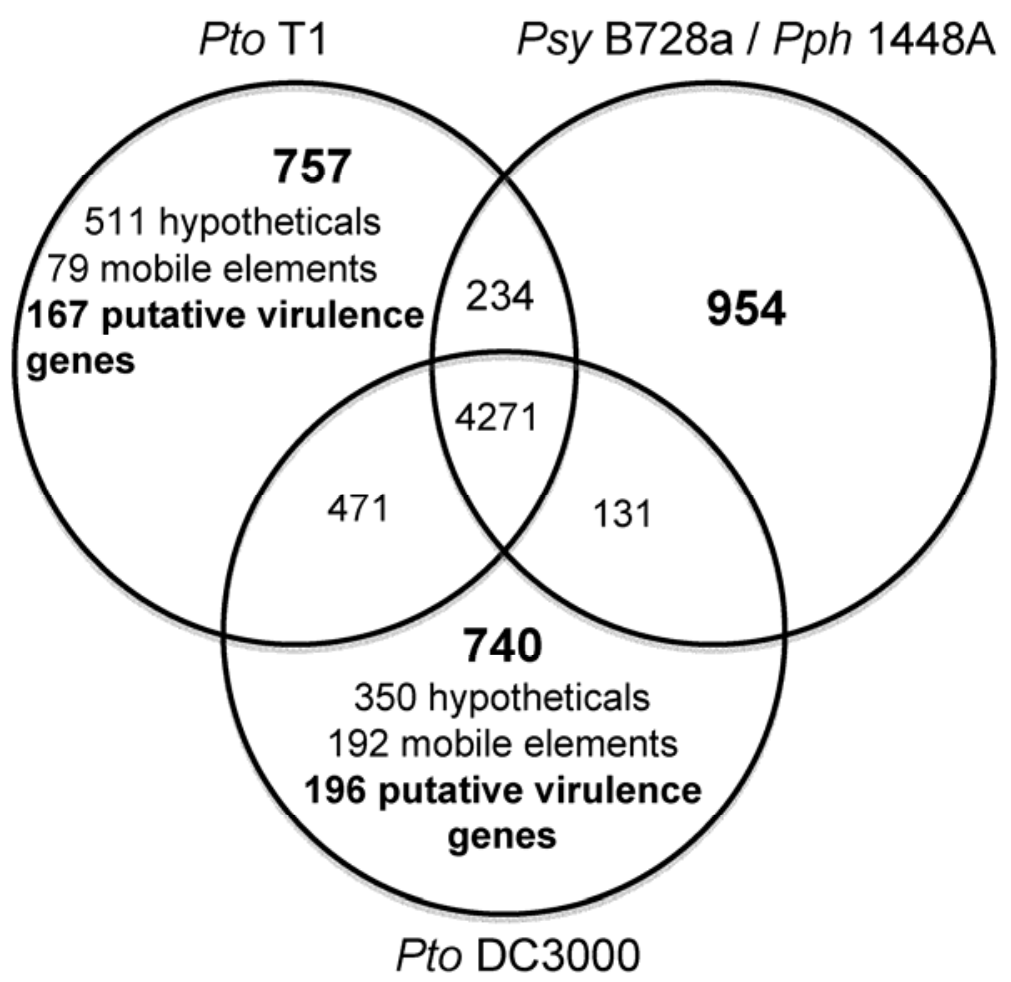

Fig. 3. Venn Diagram comparing the protein repertoire of Pseudomonas syringae pv. tomato (Pto) $\mathrm{T} 1$ with that of the completely sequenced genomes of $P$. syringae pv. tomato DC3000, Pseudomonas syringae pv. syringae (Psy) B728a, and P. syringae pv. phaseolicola (Pph) 1448A. Proteins from the B728a and 1448A genomes were combined. Numbers of predicted proteins for each section are indicated. An interactive version of this figure in which the different sections of the diagram are hyperlinked to corresponding lists of proteins are available on the Vinatzer lab's website. 
represents the most interesting class of genes, with potential involvement in host specificity through either elicitation of $A$. thaliana defenses or contribution to virulence on tomato. DC3000 contains a similar number of gene products (196) that are unique among the four strains and have some functional annotation, which may account for the host range extension of DC3000 to A. thaliana. The hypothetical proteins unique to T1 or DC3000 may be found to also encode host specificity fac-

Table 2. In planta adenylate cyclase activity in Nicotiana benthamiana of Pseudomonas syringae pv. tomato T1 effector candidate-Cya fusion proteins

\begin{tabular}{lcc}
\hline & \multicolumn{2}{c}{ pmol cAMP/ $\boldsymbol{\mu g}$ protein } \\
\cline { 2 - 3 } Cya fusion protein & $\mathbf{D C 3 0 0 0}$ (T3SS+) $^{\mathbf{a}}$ & $\mathbf{5 1 1 2}(\mathbf{T 3 S S}-)$ \\
\hline AvrRpt2 (PSPTOT1_2469) & $371.3 \pm 47.8$ & $19.1 \pm 6.7$ \\
AvrA (PSPTOT1_4933) & $191.3 \pm 70.8$ & $0.6 \pm 0.2$ \\
HopAE (PSPTOT1_0516) & $217.2 \pm 17.8$ & $0.7 \pm 0.2$ \\
HopAS1 (PSPTOT1_1672) & $136.3 \pm 11.6$ & $0.6 \pm 0.2$ \\
PSPTOT1_0854 & $15.3 \pm 5.4$ & $16.1 \pm 5.2$ \\
EELORF2 (PSPTOT1_4759) & $11.3 \pm 3.2$ & $10.7 \pm 4.0$ \\
\hline
\end{tabular}

a T3SS = type III secretion system.

${ }^{\mathrm{b}}$ Only the first $1 \mathrm{~kb}$ of coding sequence was tested. tors, if additional analyses are able to demonstrate which ones indeed code for expressed proteins.

A comparison of the predicted protein repertoire of T1 with all finished Pseudomonas genomes was also performed. Results can be queried in the supplemental data section at Virginia Tech's PtoT1 genome website.

\section{Prediction of the T3SS effector repertoire of T1 and comparison with the $\mathrm{DC} 3000$ effector repertoire.}

Comparison of major virulence factors identified in DC3000 (Lindeberg et al. 2008) with those encoded by T1 reveals that all major classes of virulence proteins appear to be present, with the exception of those encoding the toxin coronatine and a subset of T3E. To investigate the hypothesis that $\mathrm{T} 3 \mathrm{E}$ are primarily responsible for the differences in host range observed between T1 and DC3000, a thorough analysis of T3E in T1 was conducted. The list of all known $P$. syringae effectors maintained at the Pseudomonas-Plant Interaction website was compared against the T1 genome using BLAST analysis. A subset of the T1 effector genes lacking orthologs in DC3000 (avrA, avrRpt2, hopAS1, and hopAE1) were cloned and expressed as Cya fusion proteins in DC3000, and translocation was confirmed as previously described (Schechter et al. 2004).

Table 3. Repertoires of type III secretion system (T3SS) effectors and T3SS-independent genes in Pseudomonas syringae pv. tomato T1 compared with $P$. syringae pv. tomato DC $3000^{\mathrm{a}}$

\begin{tabular}{|c|c|c|c|c|c|}
\hline DC3000 & Locus tag & hrp Box & T1 & Locus tag & hrp box \\
\hline \multicolumn{6}{|c|}{ T3E orthologs deployed by both DC3000 and T1 } \\
\hline avrE1 & PSPTO_1377 & Yes & avrE1 & PSPTOT1_0672 & Yes \\
\hline avrPtoB (hopAB2) & PSPTO_3087 & Yes & hopAB3 & PSPTOT1_1462 & Yes \\
\hline hopC1 & PSPTO_0589 & Yes & hopC1-1 & PSPTOT1_1097 & Yes \\
\hline hopD1 & PSPTO_0876 & Yes & hopD1 & PSPTOT1_2827 & Yes \\
\hline hopF2 & PSPTO_0502 & Yes (operon) & hopF2 & PSPTOT1_0639 & Yes (operon) \\
\hline hopH1 & PSPTO_0588 & Yes & hopH1 & PSPTOT1_1413 & Yes \\
\hline hopI1 & PSPTO_4776 & Yes & hopI1 & PSPTOT1_0569 & Yes \\
\hline hopO1-1 & PSPTO_A0018 & Yes & hopO1-1 & PSPTOT1_4763 & Yes (operon) \\
\hline hopQ1-1 & PSPTO_0877 & Yes & hopQ1-1 & PSPTOT1_2826 & Yes \\
\hline hopR1 & PSPTO_0883 & Yes & hopR1 & PSPTOT1_5535 & Yes \\
\hline hopT1-1 & PSPTO_A0019 & Yes (operon) & hopT1-1 & PSPTOT1_4762 & Yes (operon) \\
\hline hopY1 & PSPTO_0061 & Yes & hopY1 & PSPTOT1_1266 & Yes \\
\hline hopAA1-1 & PSPTO_1372 & Yes & hopAA1 & PSPTOT1_0677 & Yes \\
\hline hopAF1 & PSPTO_1568 & Yes & hopAF1 & PSPTOT1_4398 & Yes \\
\hline \multicolumn{6}{|c|}{ T3E orthologs deployed by DC3000 alone } \\
\hline hopA1 & PSPTO_5354 & Yes (operon) & hopA1' & PSPTOT1_2530 & Yes (operon) \\
\hline hopB1 & PSPTO_1406 & Yes (operon) & hopB1' & PSPTOT1_0643 & Yes (operon) \\
\hline hopM1 & PSPTO_1375 & Yes (operon) & hopM1' & PSPTOT1_0674 & Yes (operon) \\
\hline avrPto & PSPTO_4001 & Yes & Absent & & \\
\hline hopE1 & PSPTO_4331 & Yes & Absent & & \\
\hline hopG1 & PSPTO_4727 & Yes & Absent & & \\
\hline hopK1 & PSPTO_0044 & Yes & Absent & & \\
\hline hopN1 & PSPTO_1370 & Yes & Absent & & \\
\hline hopU1 & PSPTO_0501 & Yes & Absent & & \\
\hline hopV1 & PSPTO_4720 & Yes & Absent & & \\
\hline hopX1 & PSPTO_A0012 & Yes & Absent & & \\
\hline hopAA1-2 & PSPTO_4718 & Yes & Absent & & \\
\hline hopAM1-1 & PSPTO_1022 & Yes & Absent & & \\
\hline hopAM1-2 & PSPTO_A0005 & Yes & Absent & & \\
\hline hopAO1 & PSPTO_4722 & Yes & Absent & & \\
\hline \multicolumn{6}{|c|}{$\mathrm{T} 3 \mathrm{E}$ orthologs deployed by $\mathrm{T} 1$ alone } \\
\hline hopS1' & PSPTO_4597 & Yes (operon) & hopS1 & PSPTOT1_0510 & Yes (operon) \\
\hline hopPtoAG:: ISPssy & PSPTO_0901 & Yes & hopAG1 & PSPTOT1_5517 & Yes \\
\hline hopAH1 & PSPTO_0905 & No & hopAH1 & PSPTOT1_5516 & Yes (operon) \\
\hline hopAI1 & PSPTO_0906 & No & hopAI1 & PSPTOT1_5515 & Yes (operon) \\
\hline hopAS1' & PSPTO_0474 & Yes & hopAS1 & PSPTOT1_1672 & Yes \\
\hline \multirow[t]{2}{*}{ Absent } & & & hopAE1 & PSPTOT1_0516 & Yes \\
\hline & & & & \multicolumn{2}{|c|}{ Continued on following pa } \\
\hline
\end{tabular}

\footnotetext{
${ }^{a}$ Reasons for lack of deployment include: absence of the structural gene; truncation, indicated by a single quotation; truncation by an insertion sequence, indicated by a double colon and the insertion sequence name; absence of a functional hrp promoter. Light gray background indicates that either one or both expression and translocation have not been fully evaluated; dark gray background indicates that either one or both expression and translocation are absent or unlikely; and no background shading indicates orthologs are likely functional.
} 
The putative T1 effector genes hopW1 and $a v r D$ were not tested for translocation, since these two genes are probably not contributing to $A$. thaliana resistance to $\mathrm{T} 1$; the effector gene hopWl is present in $P$. syringae pv. maculicola ES4326, well known to cause disease on many $A$. thaliana ecotypes, including Col-0, and $a v r D$ was shown not to reduce bacterial growth of ES4326 in A. thaliana (Wanner et al. 1993).

To identify those effector genes likely to be expressed and to identify any novel effectors that might be present in the T1 genome, a list of predicted binding sites for the HrpL alternate sigma factor was generated for the T1 genome as previously described (Fouts et al. 2002; Lindeberg et al. 2006; Vencato et al. 2006), and the candidate HrpL-regulated genes were analyzed for the presence of conserved N-terminal motifs consistent with type III secretion. Among the candidates with hrp promoters and plausible translocation motifs were T1 orthologs of the D3000 exchangeable effector locus open reading frame (ORF)2 gene product and of the $P$. syringae pv. syringae B728a gene encoding Psy_0737, though neither was found to be translocated. Cya test results are shown in Table 2. A list of the T1 hrp regulon and putative effector genes is shown in Table 3, together with the verified DC3000 hrp regulon and effector repertoire. T1 effectors have been added to the effector database at the Pseudomonas-Plant Interaction website.
Comparison of the effector repertoires for T1 and DC3000 reveals surprising differences despite the otherwise high degree of similarity and shared tomato host. Of the effectors that are likely to be deployed, as determined by the presence of an hrp box and intact coding region, only 14 are shared between the two, while as many as 15 are present only in the DC3000 genome and 11 only in the T1 genome. With regard to some of the best-studied T3SS effectors, T1 alone deploys AvrRpt2 (with only two amino-acid differences when compared with AvrRpt $2_{\text {Pto JL1065, }}$, the allele originally cloned by R. Innes, [Innes et al. 1993]), while DC3000 alone produces AvrPto, HopU1, HopX1, and two HopAM1 paralogs. HopX1 is of particular interest, given that this gene is conserved in 1448a, B728a, and at least ten other $P$. syringae pathovars (Charity et al. 2003; Deng et al. 2003). HopM1 also appears to be deployed by DC300 alone, as the presence of a frameshift in the T1 ortholog reduces the likelihood of functionality. A homolog of HopAB2 (AvrPtoB) is encoded by both genomes but shows evidence of extensive divergence relative to flanking DNA, indicative of high selection pressure and of sufficient difference to warrant inclusion in a different subgroup (HopAB3) relative to the ortholog present in DC3000 (HopAB2).

Because of the draft status of the T1 genome sequence, there is uncertainty regarding a small number of effectors. The effec-

Table 3. Continued from preceding page

\begin{tabular}{|c|c|c|c|c|c|}
\hline DC3000 & Locus tag & hrp Box & T1 & Locus tag & hrp box \\
\hline \multicolumn{6}{|c|}{ T3E orthologs deployed by T1 alone (continued) } \\
\hline Absent & & & hopW1 & PSPTOT1_3130 & Yes \\
\hline Absent & & & avrA & PSPTOT1_4933 & Yes \\
\hline Absent & & & avrRpt2 & PSPTOT1_2469 & Yes \\
\hline Absent & & & avrD1 & PSPTOT1_0872 & Yes \\
\hline \multicolumn{6}{|c|}{ T3E orthologs deployed by neither DC 3000 nor T1 } \\
\hline hopO1-3' & PSPTO_4592 & No & hopO1-3 & PSPTOT1_0506 & No \\
\hline hopT2 & PSPTO_4590 & No & hopT2 & PSPTOT1_0505 & No \\
\hline hopAH2-1 & PSPTO_3292 & No & hopAH2-1 & PSPTOT1_5346 & No \\
\hline hopAH2-2 & PSPTO_3293 & No & hopAH2-2 & PSPTOT1_5345 & No \\
\hline hopD::IS52 & PSPTO_4724 & Yes & Absent & & \\
\hline hopQ1-2 & PSPTO_4732 & No & Absent & & \\
\hline hopAT1' & PSPTO_5618 & No & Absent & & \\
\hline Absent & & & hopC1-2' & PSPTOT1_1415 & Yes \\
\hline Absent & & & hopAW (C-term) & PSPTOT1_4687 & No \\
\hline \multicolumn{6}{|l|}{ T3E status in DC3000 not fully evaluated } \\
\hline hopO1-2 & PSPTO_4594 & Possible (operon) & hopO1-2 & PSPTOT1_0508 & Possible (operon) \\
\hline hopS2 & PSPTO_4588 & Yes (operon) & hopS2 & PSPTOT1_0503 & Operon \\
\hline hopT1-2 & PSPTO_4593 & Yes & hopT1-2 & PSPTOT1_0507 & Possibly (operon) \\
\hline hopAN1 & PSPTO 5061 & No & hopAN1 & PSPTOT1 3476 & No \\
\hline hopAD1 & PSPTO_4691 & Yes & Absent & & \\
\hline hopAQ1 & PSPTO_4703 & Possible & Absent & & \\
\hline \multicolumn{6}{|l|}{ Harpins, pilus-associated, helpers } \\
\hline hrpA1 & PSPTO_1381 & Yes & hrpA1 & PSPTOT1_0668 & Yes \\
\hline hrpK1 & PSPTO_1405 & Yes & hrpK1 & PSPTOT1_0644 & Yes \\
\hline hrpW1 & PSPTO_1373 & Yes & hrpW1 & PSPTOT1_0676 & Yes \\
\hline hrpZ1 & PSPTO_1382 & Yes & hrpZ1 & PSPTOT1_0667 & Yes \\
\hline hopP1 & PSPTO_2678 & Yes & hopP1 & PSPTOT1_5231 & Yes \\
\hline hopAK1 & PSPTO_4101 & Yes & hopAK1 & PSPTOT1_2049 & Yes \\
\hline hrpH & PSPTO_1378 & Yes & hrpH & PSPTOT1_0671 & Yes \\
\hline hopAJ1 & PSPTO_0852 & Yes & Absent & & \\
\hline \multicolumn{6}{|c|}{ Non-Hop hrp regulon (hrp promoters experimentally confirmed in other strains) } \\
\hline apbE & PSPTO_2105 & Yes & apbE & PSPTOT1_3672 & Yes \\
\hline Conserved hypothetical (truncated?) & PSPTO_5617 & Yes & Conserved hypothetical & PSPTOT1_3153 & Yes \\
\hline MATE efflux & PSPTO_0370 & Yes & MATE efflux & PSPTOT1_4882 & Yes \\
\hline iaaL & PSPTO_0371 & Yes (operon) & iaaL & PSPTOT1_4881 & Yes \\
\hline Sugar transport & PSPTO_3489 & Yes & Sugar transport & PSPTOT1_4786 & Yes \\
\hline Sugar transport & PSPTO_3488 & Yes (operon) & Sugar transport & PSPTOT1_4787 & Yes (operon) \\
\hline Peptidase & PSPTO_0524 & Yes & peptidase & PSPTOT1_1629 & Yes \\
\hline Conserved hypothetical & PSPTO_1409 & Yes (operon) & Conserved hypothetical & PSPTOT1_0640 & No \\
\hline alc dehydrog operon & PSPTO_0834-36 & Yes & Absent & & \\
\hline Hypothetical & PSPTO_4733 & Yes & Absent & & \\
\hline Hypothetical & PSPTO_4733 & Yes & Absent & & \\
\hline
\end{tabular}


tor hopD1 had a frameshift in the first 454 pyrosequencing assembly. However, upon resequencing the gene from a polymerase chain reaction (PCR) product, it became apparent that two full-length copies of the gene with one alternate nucleotide in position 927 were wrongly assembled into one contig and both nucleotides were integrated into the sequence. Only one copy of the gene is currently annotated, since we do not know the location of the second copy. Homologs of hopCl also appear to be present in two copies in T1; however, in this instance the two copies were assembled correctly in separate contigs. A frameshift error present in one of the two copies

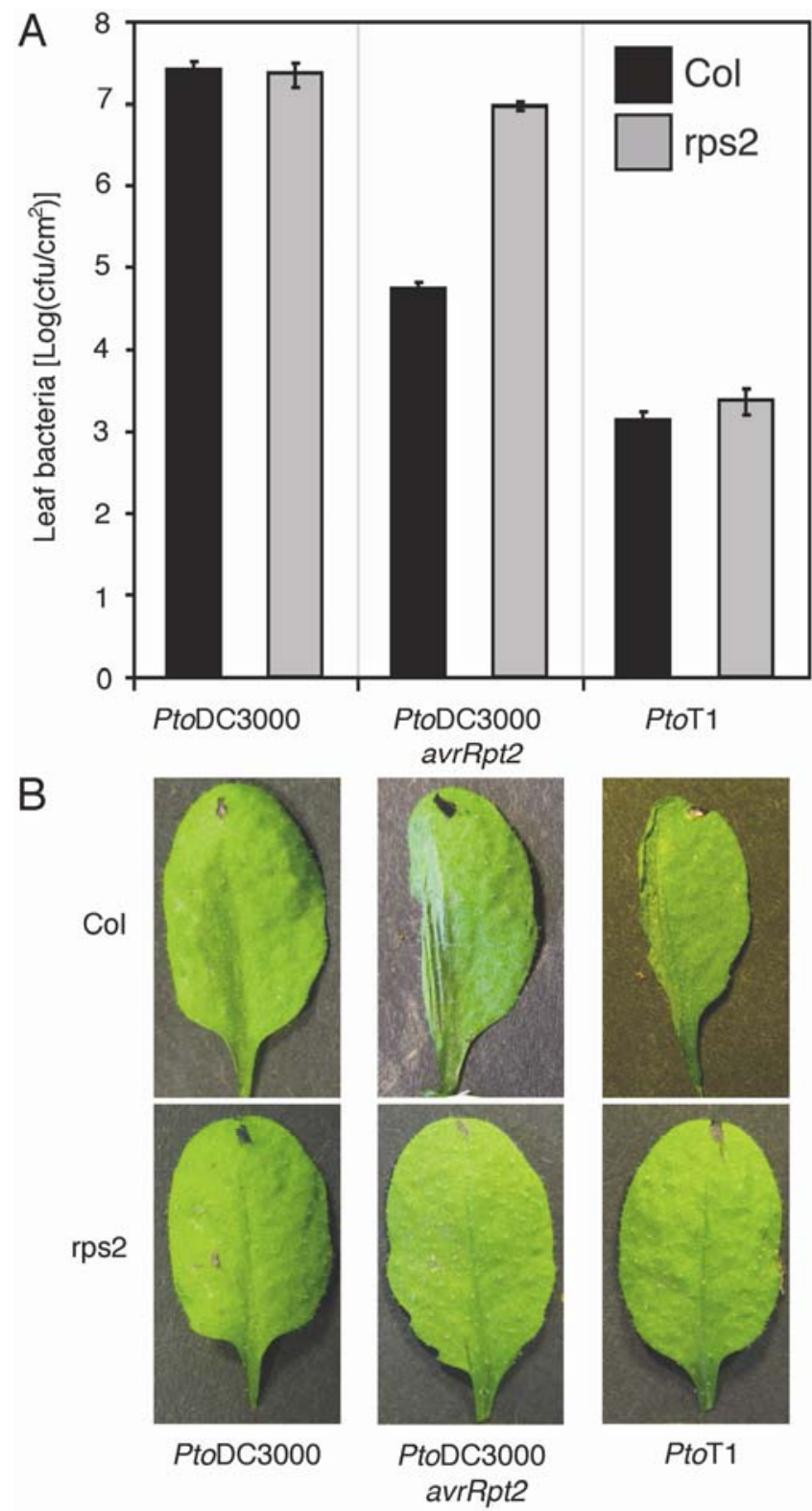

Fig. 4. Comparison of in planta growth of Pseudomonas syringae pv. tomato (Pto) DC3000, DC3000 expressing AvrRpt2, and T1 on Arabidopsis thaliana ecotype Col-0 and Col-0 rps 2-101c mutated in the RPS2 resistance gene. A, Plants were inoculated by spraying bacteria at an optical density at $600 \mathrm{~nm}\left(\mathrm{OD}_{600}\right)$ of 0.1 , and CFU per square centimeter was determined 3 days later for six leaf disks per isolate and plant. While DC3000 expressing avrRpt2 grew statistically significantly more in the Col-0 rps2-101c plants than in the Col-0 plants $(P<0.01)$, growth of T1 was not statistically significantly different on the Col-0 rps $2-101 \mathrm{c}$ plants comapred with Col-0 plants, based on Student's $t$-test $(P>0.1)$. B, Bacteria were infiltrated into leaves of $A$. thaliana Col-0 and Col-0 rps2-101c at an $\mathrm{OD}_{600}$ of 0.3 , and pictures were taken $16 \mathrm{~h}$ later. was confirmed after resequencing the gene from a PCR product. The 412-bp-long 454 contig 00076 has similarity with the $3^{\prime}$ end of the hopAW $1_{\mathrm{Pph} 1448 \mathrm{~A}}$ gene. The $5^{\prime}$ end is not present in either the 454 or the Solexa draft genome sequences, suggesting that the copy of hopAWl in T1 is most likely a pseudogene.

The presence of avrRpt 2 in the T1 genome is not sufficient to explain the inability of $\mathrm{T} 1$ to cause disease in $A$. thaliana.

The observed HR caused by $\mathrm{T} 1$ on A. thaliana 'Columbia' and its inability to replicate and to cause disease on the other tested A. thaliana ecotypes suggests a "gene for gene" interaction between one of the T1-specific effectors and an $A$. thaliana resistance gene. The presence of the avrRpt 2 effector gene in the T1 genome makes the well-known interaction between avrRpt 2 and the cognate $A$. thaliana resistance gene RPS2 (Mindrinos et al. 1994) the prime suspect. To evaluate the role of AvrRpt $2_{\text {Pto T1 }}$ in resistance, DC3000, DC3000 expressing AvrRpt $2_{\text {Pto JL1065, }}$, and T1 were compared for growth and presence of disease symptoms between A. thaliana 'Columbia and the rps 2 mutant line rps2-101c of A. thaliana 'Columbia (Mindrinos et al. 1994). As shown in Figure 4A, T1 population densities remained at a low level similar to those of the T3SSS-deficient DC3000 mutant (Fig. 1), even in the absence of the avrRpt2-RPS2 interaction. However, no HR could be detected on A. thaliana 'Columbia' rps2-101c (Fig. 4B). These observations suggest that the avrRpt2-RPS2 interaction is the source of the HR elicited by T1 on A. thaliana 'Columbia' but does not fully explain resistance of $A$. thaliana to $\mathrm{T} 1$.

Can gene for gene interactions other than avrRpt2-RPS2 explain the inability of $\mathrm{T} 1$ to cause disease in $A$. thaliana?

Since gene for gene interactions are not always accompanied by a HR (Gassmann 2005), the absence of a HR during T1 infection of the A. thaliana 'Columbia' rps 2 mutant line does not exclude the possibility that ETI induced by T1 effec-

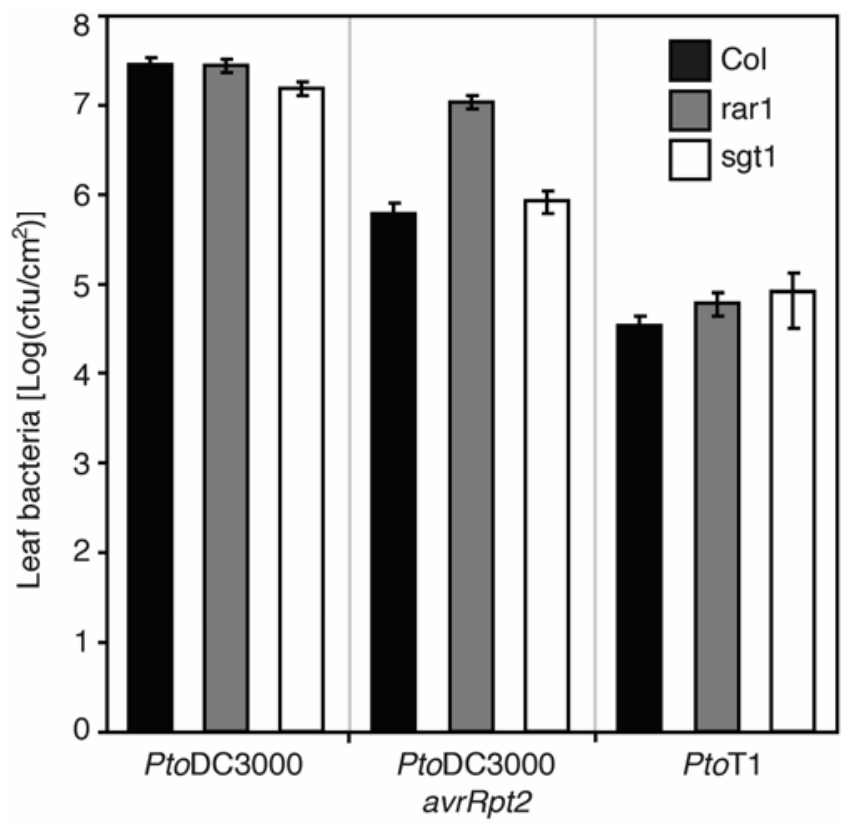

Fig. 5. Comparison of in planta growth of Pseudomonas syringae pv. tomato (Pto) DC3000, DC3000 expressing AvrRpt2, and Pseudomonas syringae pv. tomato T1 on wild-type Arabidopsis thaliana ecotype Col-0 and $A$. thaliana Col-0 mutated in the genes $S G T 1$ and $R A R 1$, respectively. Plants were inoculated, and CFU were counted 3 days postinfection. While DC3000 expressing avrRpt2 grew statistically significantly more in Col-0 plants mutated in $R A R 1$ than in Col-0 plants $(P<0.0001)$, growth of T1 was not statistically significantly different in plants mutated in $R A R 1$ or $S C T 1$ as compared with Col-0 plants, based on Student's $t$-test $(P>0.1)$. 
tors other than AvrRpt 2 is the determining factor in the inability of $\mathrm{T} 1$ to cause disease in A. thaliana. This possibility can be evaluated using $A$. thaliana lines mutagenized in the genes $R A R I$ or $S G T 1 b$, previously shown to be essential for ETI in $A$. thaliana (Azevedo et al. 2006). Specifically, SGT1b was shown to be necessary for various Hyaloperonospora parasitica-A. thaliana gene for gene interactions and a mutation in $R A R l$ was shown to reduce $A$. thaliana resistance to the $P$. syringae effectors AvrRpt2, AvrRpm1, and AvrRps4 (Austin et al. 2002). The SGT1b homolog SGT1a was not required for resistance triggered by these $P$. syringae effectors (Azevedo et al. 2006), nor could it complement a mutation in SGT1b during Hyaloperonospora parasitica-A. thaliana gene-for-gene interactions (Austin et al. 2002), except when overexpressed (Azevedo et al. 2006). Therefore, we reasoned that if ETI is induced during the T1-A. thaliana interaction by effectors other than AvrRpt2, T1 growth on SGT1b or RAR1 mutant lines of $A$. thaliana might be increased. However, as shown in Figure 5, while growth of DC3000 expressing avrRpt2 was increased 10-fold in the RARl mutant, T1 growth was not significantly different in either the $S G T 1 b$ or the RARI mutant as compared with wild-type A. thaliana 'Columbia'. This was also true for the $P$. syringae pv. tomato isolate Max13 (Yan et al. 2008), from which avrRpt2 is naturally missing, and for another $P$. syringae pv. tomato isolate with a disruption of avrRpt2 (data not shown). Both isolates are identical to T1 based on our published MLST analysis (Yan et al. 2008). Therefore, while immunity triggered by AvrRpt 2 and possibly other effectors contributes to A. thaliana resistance to T1 and similar $P$. syringae pv. tomato isolates, other mechanisms independent of ETI can be expected to play critical roles also.

\section{DISCUSSION}

Although T1 and DC3000 are both considered to be members of $P$. syringae pv. tomato, we have previously shown that they belong to two closely related but clearly distinct phylogenetic groupings with distinct host ranges (Yan et al. 2008). While T1-like strains cause disease only on tomato and are found on tomato with bacterial speck disease all over the world, DC3000-like strains cause disease on A. thaliana, cauliflower, and tomato and have been isolated mainly from family Brassicaceae and wild Solanaceae plants. Here, we show that resistance of $A$. thaliana to T1-like strains occurs in several ecotypes and that T1-like strains only reach population densities similar to a T3SS-deficient mutant of DC3000. These findings suggest that T1-like strains share a fundamental difference relative to DC3000 that prevents them from being pathogens of $A$. thaliana.

To date, the basis of nonhost resistance exhibited by $A$. thaliana toward $P$. syringae strains has been best studied using strains of $P$. syringae pv. phaseolicola (de Torres et al. 2006; Ham et al. 2007; Lu et al. 2001). However, the large number of differences between the $P$. syringae pv. phaseolicola strains and DC3000 greatly complicates identification of pathogenhost interaction factors using genome comparison. In contrast, the T1 genome exhibits a high level of similarity to DC3000 with the majority of differences consisting of short hypothetical genes distributed throughout otherwise colinear regions. This suggests that many of these hypothetical genes may not be true coding sequences.

A surprising outcome of this study is that, while the two $P$. syringae pv. tomato genomes exhibit a high level of overall similarity, their repertoires of T3SS effectors are strikingly diverse. This indicates that T3SS effectors may play an important role in determining the difference in host specificity between the two strains, particularly with regard to A. thaliana. Effectors present in T1 but absent in DC3000 could lead to gene for gene resistance of $A$. thaliana to T1, while effectors present in DC3000 but missing in T1 could account for the inability of T1 to suppress ETI or PTI. Although T1 also lacks biosynthetic genes for the phytotoxin coronatine, this toxin has no demonstrated role in host range determination.

Of the 11 effectors present in the $\mathrm{T} 1$ genome but not in DC3000, the most notable is the well-characterized AvrRpt2, indirectly recognized in A. thaliana by the resistance gene product RPS2 upon degradation of RIN4 (Axtell and Staskawicz 2003; Kim et al. 2005; Mackey et al. 2003). However, it has been shown here that the avrRpt2-RPS2 gene for gene interaction is not the sole mechanism of $A$. thaliana resistance to T1, since $\mathrm{T} 1$ growth on $A$. thaliana mutated in the RPS 2 gene is not increased compared with A. thaliana wild-type plants and symptoms are not increased. Moreover, additional putative gene for gene interactions are also insufficient to explain resistance of $A$. thaliana to $\mathrm{T} 1$, since the genes $R A R 1$ and SGT1, known to contribute to gene for gene resistance, are not necessary for this resistance. Therefore, we hypothesize that $A$. thaliana resistance to $\mathrm{T} 1$ is based on multiple parallel defense pathways, as previously observed for the $P$. syringae pv. phaseolicola-A. thaliana interaction (Ham et al. 2007). To identify the pathways involved, future work will be directed towards expression of DC3000 effectors in T1 and evaluation of their phenotypes in various single- and multiple-defense mutants of A. thaliana.

The two DC3000 effectors that probably have the greatest potential of conferring increased virulence of $\mathrm{T} 1$ on $A$. thaliana are avrPto $1_{\mathrm{PtoDC} 3000}$ and hopM $1_{\mathrm{PtoDC} 3000}$, which have both been shown to be important virulence factors during DC3000 infection of A. thaliana (Hauck et al. 2003; Nomura et al. 2006). However, the $P$. syringae pv. tomato isolate JL1065, which is closely related to the T1-like strains (although phylogenetically distinct [Yan et al. 2008]) expresses AvrPto1 as well as HopM1 (data not shown) but is still unable to cause disease on A. thaliana even in the absence of the avrRpt2RPS 2 gene for gene interactions (Yan et al. 2008). Moreover, hopM1 and avrE1 have redundant function in the DC3000-A. thaliana interaction (DebRoy et al. 2004) and $a v r E 1$ is present in the T1 genome (DNA identity, 95\%). This makes it unlikely that simply expressing hopM $1_{\mathrm{Pto} \text { DC3000 }}$ in $\mathrm{T} 1$ could render T1 pathogenic on A. thaliana. Nonetheless, we performed this experiment and, as expected, could not observe any increase in bacterial growth or formation of disease symptoms in $A$. thaliana 'Columbia' (data not shown).

Based on the results obtained so far, we predict that identification of gene products capable of conferring increased growth or symptomology of $\mathrm{T} 1$, or both, in A. thaliana will require the

Table 4. Pseudomonas syringae pv. tomato isolates used in this study

\begin{tabular}{|c|c|c|}
\hline Isolate name & Description & Reference \\
\hline DC3000 & $\begin{array}{l}\text { Arabidopsis thaliana and tomato pathogen; rifampicin-resistant derivative of strainNCPPB } \\
\text { 1106, isolated from tomato on the island of Guernsey (U.K.) by R. A. Lelliott. }\end{array}$ & $\begin{array}{l}\text { Buell et al. 2003; Cuppels 1986; Yan } \\
\text { et al. } 2008\end{array}$ \\
\hline DC3000 CUCPB5112 & Type III secretion system-deficient DC3000, because of deletion of the $h r c C$ gene & Penaloza-Vazquez et al. 2000 \\
\hline DC3000 pLH12 & DC3000 expressing AvrRpt $2_{\text {Pto JL1065 }}$ from its native promoter on plasmid pLAFR3 & Whalen et al. 1991 \\
\hline T1 & Isolated from tomato in Canada by G. Bonn (Agriculture \& Agri-Food Canada) & Whalen et al. 1991; Yan et al. 2008 \\
\hline
\end{tabular}


simultaneous mutation of several $A$. thaliana defense pathways in combination with expression of one or more DC3000 effectors in T1. It is also possible that the inability of T1 to grow and cause disease on $A$. thaliana is due to yet unknown incompatibility mechanisms that are independent of characterized defense pathways and effectors, for example, gene for gene resistance independent of $R A R I$ and $S G T 1 b$ or nutritional requirements of $\mathrm{T} 1$ not met by the A. thaliana apoplast. The identified gene differences between T1 and DC3000 and allelic differences between shared genes represent an ideal unbiased starting point for experimental characterization of these mechanisms.

In conclusion, this study demonstrates that the comparison of a high quality $P$. syringae draft genome sequence with a completely assembled genome sequence of a closely related strain represents a powerful approach for identification of differences in gene content between strains. In particular, draft genome sequencing is an effective and rapid means of identifying the complete effector repertoire of individual $P$. syringae strains when used in combination with BLAST analysis and experimental testing of effector candidates identified by proximity to hrp box motifs. Experimental dissection of the roles of strain-specific effectors and other candidate host specificity genes identified through genome comparison is expected to reveal important insights into the specific interactions that govern differences in host range observed for the two strains compared here. Additional draft genome sequences currently being generated for other $P$. syringae strains by our group and by other researchers can be expected to take $P$. syringae genomics to new levels, accelerating the discovery of yet unknown aspects of molecular $P$. syringae-plant interactions.

\section{MATERIALS AND METHODS}

\section{Bacterial strains and growth media.}

Bacterial strains are listed in Table 4. P. syringae isolates were grown at $28^{\circ} \mathrm{C}$ on King's broth (King et al. 1954) agar plates supplemented with the following antibiotics at the following concentrations when necessary to maintain plasmids: kanamycin $(50 \mu \mathrm{g} / \mathrm{ml})$, tetracycline $(15 \mu \mathrm{g} / \mathrm{ml})$, and gentamycin $(10 \mu \mathrm{g} / \mathrm{ml})$.

\section{Plant growth and infections.}

For bacterial growth in planta and disease assays, $A$. thaliana plants were grown with a 16-h day and temperature was kept at $23^{\circ} \mathrm{C}$ during the day and $19^{\circ} \mathrm{C}$ during the night. Plants were infected at an age of 3 weeks, and bacterial population sizes were determined 3 days after infection as previously described (Yan et al. 2008). Differences between population sizes were statistically analyzed in the JMP 7 program (SAS Institute, Cary, NC, U.S.A.) using Student's $t$-test.

\section{Genome sequencing and assembly.}

For 454 sequencing, T1 (G. Martin lab glycerol stock \#3876) was grown overnight in $1 \mathrm{ml}$ of liquid media. Genomic DNA was extracted using a Wizard DNA purification kit (product \#A1120; Promega, Madison, WI, U.S.A.) and by following the manufacturer's protocol for isolation of genomic DNA from gram-negative bacteria. The optical densities at 260 and $280 \mathrm{~nm}$ were determined using a NanoDrop ND-1000 spectrophotometer and were found to be 2.08. A total of $60 \mu \mathrm{g}$ of DNA was precipitated in ethanol and $3 \mathrm{M} \mathrm{NaAC}$. An aliquot of $10 \mu \mathrm{g}$ of DNA was then used for single-stranded template DNA library construction and a titration run was carried out on the GS FLX sequencer (Roche, Basel, Switzerland) in accordance with the manufacturer's protocol. It was determined that the ratio of one DNA molecule per bead was the optimum.
Subsequently, a bulk emulsion PCR was carried out using this ratio, to provide the beads to run a full LR 70 plate. A total of one 7 -h run was performed. The quality filtered reads were then assembled into contigs using the Newbler assembler.

For Solexa sequencing, DNA was prepared from bacteria grown in L medium using the Puregene Genomic DNA purification kit (Gentra Systems, Inc., Minneapolis) according to manufacturer's instructions. Libraries for single-read Illumina sequencing were prepared from $5 \mu \mathrm{g}$ of DNA using a Genomic DNA sample prep kit (Illumina, Inc., Cambridge). DNA was fragmented by nebulization for $6 \mathrm{~min}$ at a pressure of $32 \mathrm{psi}$. For end-repair and phosphorylation, sheared DNA was purified using the QIAquick nucleotide removal kit (Qiagen, Crawley, U.K.). The end-repaired DNA was A-tailed and adaptors were ligated according to manufacturer's instructions. Size fractionation and purification of ligation products was performed using a 5\% polyacrylamide gel run in tris-borateEDTA at $180 \mathrm{~V}$ for $120 \mathrm{~min}$. Gel slices were cut containing DNA in the 130- to 150 -bp range. DNA was than extracted using $0.3 \mathrm{M}$ sodium acetate and $2 \mathrm{mM}$ EDTA ( $\mathrm{pH}$ 8.0), followed by ethanol precipitation. Using 18 PCR cycles with primer 1.1 and 2.1 (Illumina, Inc.), 5' adaptor extension and enrichment of the library was performed. The library was finally purified using a QIAquick PCR purification kit and adjusted to a concentration of $10 \mathrm{nM}$ in $0.1 \%$ Tween. Flow cells were prepared according to manufacturer's instructions using cluster generation kits and a cluster station. Sequencing reactions were performed on a $1 \mathrm{G}$ genome analyzer (Illumina, Inc.). A total of $5 \mathrm{pM}$ of the library were used to achieve approximately 25,000 to 30,000 clusters per tile. Sequence reads were assembled using Velvet 0.5 (Zerbino and Birney 2008).

\section{Annotation.}

The T1 draft genome was annotated by first blasting all open reading frames longer than 33 amino acids against all sequenced genomes in genera Pseudomonas, Ralstonia, and Xanthomonas available at National Center for Biotechnology Information (NCBI) in September, 2007; and all T3SS effector genes from the $P$. syringae effector database at the Pseudomonas-Plant Interaction website, using the GRC program (A. Warren and J. C. Setubal, unpublished). All ORF with no hits were then blasted against the nonredundant database at NCBI and were analyzed using InterProScan (Quevillon et al. 2005).

\section{Comparative genomics.}

The T1 454 and Solexa draft genome sequences were aligned against the published sequence of DC3000 (Buell et al. 2003), using blastn from the NCBI BLAST software suite (Altschul et al. 1997) using default parameters except -e 1e-10 -b $1-\mathrm{v} 1$. Circular genome views of the alignments were generated using CGView (Stothard and Wishart 2005).

Protein repertoires were compared using pairwise blast (Altschul et al. 1997), 3GC (Telles et al. 2005) (used for the Venn diagrams shown in Figure 3), and OrthoMCL (Li et al. 2003), the latter of which clusters proteins in orthologous groups based on the MCL algorithm (Enright et al. 2002).

\section{Effector prediction, cloning, $P$. syringae transformation, and testing for translocation.}

T3SS effectors and other genes under the control of the HrpL sigma factor were predicted as described by Vencato and associates (2006). Effectors were cloned using the Gateway (Invitrogen, Carlsbad, CA, U.S.A.) cloning system into pENTR/SD/D-TOPO (primers available upon request), were recombined into the $P$. syringae vectors pBBRPnpt-GW-Cya and expressed in DC3000, and were tested for translocation as previously described (Schechter et al. 2004). 


\section{ACKNOWLEDGMENTS}

Work in the Vinatzer lab and pyrosequencing of $\mathrm{T} 1$ was funded by the Virginia Tech Institute for Biomedical and Public Health Sciences and the National Science Foundation (award number 0746501). N. F. Almeida was funded by Conselho Nacional de Desenvolvimento Cientifico e Tecnologico (CNPq), fellowship 200447/2007-6. Research at Cornell University and the Boyce Thompson Institute was supported by the National Science Foundation (award number DBI-0605059).

\section{LITERATURE CITED}

Altschul, S. F., Madden, T. L., Schaffer, A. A., Zhang, J., Zhang, Z., Miller, W., and Lipman, D. J. 1997. Gapped BLAST and PSI-BLAST: A new generation of protein database search programs. Nucleic Acids Res. 25:3389-402.

Angot, A., Vergunst, A., Genin, S., and Peeters, N. 2007. Exploitation of eukaryotic ubiquitin signaling pathways by effectors translocated by bacterial type III and type IV secretion systems. PLoS Pathog. 3:e3. Published online.

Austin, M. J., Muskett, P., Kahn, K., Feys, B. J., Jones, J. D., and Parker, J. E. 2002. Regulatory role of $S G T 1$ in early $R$ gene-mediated plant defenses. Science 295:2077-80.

Axtell, M. J., and Staskawicz, B. J. 2003. Initiation of RPS2-specified disease resistance in Arabidopsis is coupled to the AvrRpt2-directed elimination of RIN4. Cell 112:369-77.

Azevedo, C., Betsuyaku, S., Peart, J., Takahashi, A., Noel, L., Sadanandom, A., Casais, C., Parker, J., and Shirasu, K. 2006. Role of SGT1 in resistance protein accumulation in plant immunity. EMBO (Eur. Mol. Biol. Organ.) J. 25:2007-2016.

Bentley, D. R. 2006. Whole-genome re-sequencing. Curr. Opin. Genet. Dev. 16:545-552.

Bhavsar, A. P., Guttman, J. A., and Finlay, B. B. 2007. Manipulation of host-cell pathways by bacterial pathogens. Nature 449:827-834.

Buell, C. R., Joardar, V., Lindeberg, M., Selengut, J., Paulsen, I. T., Gwinn, M. L., Dodson, R. J., Deboy, R. T., Durkin, A. S., Kolonay, J. F., Madupu, R., Daugherty, S., Brinkac, L., Beanan, M. J., Haft, D. H., Nelson, W. C., Davidsen, T., Zafar, N., Zhou, L., Liu, J., Yuan, Q., Khouri, H., Fedorova, N., Tran, B., Russell, D., Berry, K., Utterback, T., Van Aken, S. E., Feldblyum, T. V., D'Ascenzo, M., Deng, W. L., Ramos, A. R., Alfano, J. R., Cartinhour, S., Chatterjee, A. K., Delaney, T. P., Lazarowitz, S. G., Martin, G. B., Schneider, D. J., Tang, X., Bender, C. L., White, O., Fraser, C. M., and Collmer, A. 2003. The complete genome sequence of the Arabidopsis and tomato pathogen Pseudomonas syringae pv. tomato DC3000. Proc. Natl. Acad. Sci. U.S.A. 100:10181-10186.

Charity, J. C., Pak, K., Delwiche, C. F., and Hutcheson, S. W. 2003. Novel exchangeable effector loci associated with the Pseudomonas hrp pathogenicity island: Evidence for integron-like assembly from transposed gene cassettes. Mol. Plant-Microbe Interact. 16:495-507.

Chisholm, S. T., Coaker, G., Day, B., and Staskawicz, B. J. 2006. Host-microbe interactions: Shaping the evolution of the plant immune response. Cell 124:803-814.

Cuppels, D.A. 1986. Generation and characterization of $\operatorname{Tn} 5$ insertion mutations in Pseudomonas syringae pv. tomato. Appl. Environ. Microbiol. 51:323-327.

Dangl, J. L., and Jones, J. D. 2001. Plant pathogens and integrated defence responses to infection. Nature 411:826-833.

DebRoy, S., Thilmony, R., Kwack, Y. B., Nomura, K., and He, S. Y. 2004. A family of conserved bacterial effectors inhibits salicylic acid-mediated basal immunity and promotes disease necrosis in plants. Proc. Natl. Acad. Sci. U.S.A. 101:9927-9932.

de Torres, M., Mansfield, J. W., Grabov, N., Brown, I. R., Ammouneh, H., Tsiamis, G., Forsyth, A., Robatzek, S., Grant, M., and Boch, J. 2006. Pseudomonas syringae effector AvrPtoB suppresses basal defence in Arabidopsis. Plant J. 47:368-382.

Deng, W. L., Rehm, A. H., Charkowski, A. O., Rojas, C. M., and Collmer, A. 2003. Pseudomonas syringae exchangeable effector loci: Sequence diversity in representative pathovars and virulence function in $P$. syringae pv. syringae B728a. J. Bacteriol. 185:2592-2602.

Enright, A. J., Van Dongen, S., and Ouzounis, C. A. 2002. An efficient algorithm for large-scale detection of protein families. Nucleic Acids Res. 30:1575-1584.

Feil, H., Feil, W. S., Chain, P., Larimer, F., DiBartolo, G., Copeland, A., Lykidis, A., Trong, S., Nolan, M., Goltsman, E., Thiel, J., Malfatti, S., Loper, J. E., Lapidus, A., Detter, J. C., Land, M., Richardson, P. M., Kyrpides, N. C., Ivanova, N., and Lindow, S. E. 2005. Comparison of the complete genome sequences of Pseudomonas syringae pv. syringae B728a and pv. tomato DC3000. Proc. Natl. Acad. Sci. U.S.A.
102:11064-11069.

Felix, G., Duran, J. D., Volko, S., and Boller, T. 1999. Plants have a sensitive perception system for the most conserved domain of bacterial flagellin. Plant J. 18:265-276.

Fouts, D. E., Abramovitch, R. B., Alfano, J. R., Baldo, A. M., Buell, C. R., Cartinhour, S., Chatterjee, A. K., D'Ascenzo, M., Gwinn, M. L., Lazarowitz, S. G., Lin, N. C., Martin, G. B., Rehm, A. H., Schneider, D. J., van Dijk, K., Tang, X., and Collmer, A. 2002. Genomewide identification of Pseudomonas syringae pv. tomato DC3000 promoters controlled by the HrpL alternative sigma factor. Proc. Natl. Acad. Sci. U.S.A. 99:2275-2280.

Gassmann, W. 2005. Natural variation in the Arabidopsis response to the avirulence gene hopPsyA uncouples the hypersensitive response from disease resistance. Mol. Plant-Microbe Interact. 18:1054-1060.

Ham, J. H., Kim, M. G., Lee, S. Y., and Mackey, D. 2007. Layered basal defenses underlie non-host resistance of Arabidopsis to Pseudomonas syringae pv. phaseolicola. Plant J. 51:604-616.

Hauck, P., Thilmony, R., and He, S. Y. 2003. A Pseudomonas syringae type III effector suppresses cell wall-based extracellular defense in susceptible Arabidopsis plants. Proc. Natl. Acad. Sci. U.S.A. 100:85778582.

Innes, R. W., Bent, A. F., Kunkel, B. N., Bisgrove, S. R., and Staskawicz, B. J. 1993. Molecular analysis of avirulence gene avrRpt2 and identification of a putative regulatory sequence common to all known Pseudomonas syringae avirulence genes. J. Bacteriol. 175:4859-4869.

Joardar, V., Lindeberg, M., Jackson, R. W., Selengut, J., Dodson, R., Brinkac, L. M., Daugherty, S. C., Deboy, R., Durkin, A. S., Giglio, M. G., Madupu, R., Nelson, W. C., Rosovitz, M. J., Sullivan, S., Crabtree, J., Creasy, T., Davidsen, T., Haft, D. H., Zafar, N., Zhou, L., Halpin, R., Holley, T., Khouri, H., Feldblyum, T., White, O., Fraser, C. M., Chatterjee, A. K., Cartinhour, S., Schneider, D. J., Mansfield, J., Collmer, A., and Buell, C. R. 2005. Whole-genome sequence analysis of Pseudomonas syringae pv. phaseolicola 1448A reveals divergence among pathovars in genes involved in virulence and transposition. J. Bacteriol. 187:6488-6498.

Jones, J. D., and Dangl, J. L. 2006. The plant immune system. Nature 444:323-329.

Kim, M. G., da Cunha, L., McFall, A. J., Belkhadir, Y., DebRoy, S., Dangl, J. L., and Mackey, D. 2005. Two Pseudomonas syringae type III effectors inhibit RIN4-regulated basal defense in Arabidopsis. Cell 121:749759.

King, E.O., Ward, M. K., and Raney, D. E. 1954. Two simple media for the demonstration of pyocyanin and fluorescin. J. Lab. Clin. Med. 44:201-207.

Kunze, G., Zipfel, C., Robatzek, S., Niehaus, K., Boller, T., and Felix, G. 2004. The $\mathrm{N}$ terminus of bacterial elongation factor Tu elicits innate immunity in Arabidopsis plants. Plant Cell 16:3496-3507.

Li, L., Stoeckert, C. J., Jr., and Roos, D. S. 2003. OrthoMCL: Identification of ortholog groups for eukaryotic genomes. Genome Res 13:2178189.

Li, X., Lin, H., Zhang, W., Zou, Y., Zhang, J., Tang, X., and Zhou, J. M. 2005. Flagellin induces innate immunity in nonhost interactions that is suppressed by Pseudomonas syringae effectors. Proc. Natl. Acad. Sci. U.S.A. 102:12990-12995.

Lin, N. C., and Martin, G. B. 2007. Pto- and Prf-mediated recognition of AvrPto and AvrPtoB restricts the ability of diverse Pseudomonas syringae pathovars to infect tomato. Mol. Plant-Microbe Interact. 20:806815.

Lindeberg, M., Myers, C. R., Collmer, A. and Schneider, D. J. 2008. Roadmap to new virulence determinants in Pseudomonas syringae: Insights from comparative genomics and genome organization. Mol. Plant-Microbe Interact. 21:685-700.

Lindeberg, M., Cartinhour, S., Myers, C. R., Schechter, L. M., Schneider, D. J., and Collmer, A. 2006. Closing the circle on the discovery of genes encoding Hrp regulon members and type III secretion system effectors in the genomes of three model Pseudomonas syringae strains. Mol. Plant-Microbe Interact. 19:1151-1158.

Lipka V., Dittgen, J., Bednarek, P., Bednarek, P., Bhat, R., Wiermer, M., Stein, M., Landtag, J., Brandt, W., Rosahl, S., Scheel, D., Llorente, F., Molina, A., Parker, J., Sommerville, S., and Schulze-Lefert, P. 2005. Pre- and postinvasion defenses both contribute to nonhost resistance in Arabidopsis. Science 310:1180-1183.

Lu, M., Tang, X., and Zhou, J. M. 2001. Arabidopsis NHO1 is required for general resistance against Pseudomonas bacteria. Plant Cell 13:437447.

Mackey, D., Belkhadir, Y., Alonso, J. M., Ecker, J. R., and Dangl, J. L. 2003. Arabidopsis RIN4 is a target of the type III virulence effector AvrRpt2 and modulates RPS2-mediated resistance. Cell 112:379-389.

Maiden, M. C., Bygraves, J. A., Feil, E., Morelli, G., Russell, J. E., Urwin, R., Zhang, Q., Zhou, J., Zurth, K., Caugant, D. A., Feavers, I. M., 
Achtman, M., and Spratt, B. G. 1998. Multilocus sequence typing: A portable approach to the identification of clones within populations of pathogenic microorganisms. Proc. Natl. Acad. Sci. U.S.A. 95:31403145.

Margulies, M., Egholm, M., Altman, W. E., Attiya, S., Bader, J. S., Bemben, L. A., Berka, J., Braverman, M. S., Chen, Y. J., Chen, Z., Dewell, S. B., Du, L., Fierro, J. M., Gomes, X. V., Godwin, B. C., He, W., Helgesen, S., Ho, C. H., Irzyk, G. P., Jando, S. C., Alenquer, M. L., Jarvie, T. P., Jirage, K. B., Kim, J. B., Knight, J. R., Lanza, J. R., Leamon, J. H., Lefkowitz, S. M., Lei, M., Li, J., Lohman, K. L., Lu, H., Makhijani, V. B., McDade, K. E., McKenna, M. P., Myers, E. W., Nickerson, E., Nobile, J. R., Plant, R., Puc, B. P., Ronan, M. T., Roth, G. T., Sarkis, G. J., Simons, J. F., Simpson, J. W., Srinivasan, M., Tartaro, K. R., Tomasz, A., Vogt, K. A., Volkmer, G. A., Wang, S. H., Wang, Y., Weiner, M. P., Yu, P., Begley, R. F., and Rothberg, J. M. 2005. Genome sequencing in microfabricated high-density picolitre reactors. Nature 437:376-380.

Mindrinos, M., Katagiri, F., Yu, G. L., and Ausubel, F. M. 1994. The A. thaliana disease resistance gene RPS2 encodes a protein containing a nucleotide-binding site and leucine-rich repeats. Cell 78:1089-1099.

Newman, M. A., von Roepenack-Lahaye, E., Parr, A., Daniels, M. J., and Dow, J. M. 2002. Prior exposure to lipopolysaccharide potentiates expression of plant defenses in response to bacteria. Plant J. 29:487-495.

Nomura, K., Debroy, S., Lee, Y. H., Pumplin, N., Jones, J., and He, S. Y. 2006. A bacterial virulence protein suppresses host innate immunity to cause plant disease. Science 313:220-223.

Penaloza-Vazquez, A., Preston, G. M., Collmer, A., and Bender, C. L. 2000. Regulatory interactions between the Hrp type III protein secretion system and coronatine biosynthesis in Pseudomonas syringae pv. tomato DC3000. Microbiology 146 (Pt 10):2447-2456.

Quevillon, E., Silventoinen, V., Pillai, S., Harte, N., Mulder, N., Apweiler, R., and Lopez, R. 2005. InterProScan: Protein domains identifier. Nucleic Acids Res. 33:W116-20. Published online.

Rohmer, L., Guttman, D. S., and Dangl, J. L. 2004. Diverse evolutionary mechanisms shape the type III effector virulence factor repertoire in the plant pathogen Pseudomonas syringae. Genetics 167:1341-1360.

Rose, L. E., Michelmore, R. W., and Langley, C. H. 2007. Natural variation in the Pto disease resistance gene within species of wild tomato (Lycopersicon). II. Population genetics of Pto. Genetics 175:1307-1319.

Schechter, L. M., Roberts, K. A., Jamir, Y., Alfano, J. R., and Collmer, A. 2004. Pseudomonas syringae type III secretion system targeting signals and novel effectors studied with a Cya translocation reporter. J. Bacteriol. 186:543-555.
Stothard, P., and Wishart, D. S. 2005. Circular genome visualization and exploration using CGView. Bioinformatics 21:537-539.

Telles, G. P., Brigido, M. M., Almeida, N. F., Viana, C. J., Anjos, D. A. S., and Walter, M. E. M. T 2005. A Method for Comparing Three Genomes. In: Advances in Bioinformatics and Computational Biology, J. C. Setubal and S. Verjovsky-Almeida, eds. Springer, Heidelberg, Germany.

Vencato, M., Tian, F., Alfano, J. R., Buell, C. R., Cartinhour, S., DeClerck, G. A., Guttman, D. S., Stavrinides, J., Joardar, V., Lindeberg, M., Bronstein, P. A., Mansfield, J. W., Myers, C. R., Collmer, A., and Schneider, D. J. 2006. Bioinformatics-enabled identification of the HrpL regulon and type III secretion system effector proteins of Pseudomonas syringae pv. phaseolicola 1448A. Mol. Plant-Microbe Interact. 19:1193-1206.

Wanner, L. A., Mittal, S., and Davis, K. R. 1993. Recognition of the avirulence gene avrB from Pseudomonas syringae pv. glycinea by Arabidopsis thaliana. Mol. Plant-Microbe Interact. 6:582-591.

Wei, C. F., Kvitko, B. H., Shimizu, R., Crabill, E., Alfano, J. R., Lin, N. C., Martin, G. B., Huang, H. C., and Collmer, A. 2007. A Pseudomonas syringae pv. tomato DC3000 mutant lacking the type III effector HopQ1-1 is able to cause disease in the model plant Nicotiana benthamiana. Plant J. 51:32-46.

Whalen, M. C., Innes, R. W., Bent, A. F., and Staskawicz, B. J. 1991. Identification of Pseudomonas syringae pathogens of Arabidopsis and a bacterial locus determining avirulence on both Arabidopsis and soybean. Plant Cell 3:49-59.

Yan, S., Liu, H., Mohr, T. J., Jenrette, J., Chiodini, R., Zaccardelli, M., Setubal, J. C., and Vinatzer, B. A. 2008. Role of recombination in the evolution of the model plant pathogen Pseudomonas syringae pv. tomato DC3000, a very atypical tomato strain. Appl. Environ. Microbiol. 74:3171-181.

Zerbino, D. R., and Birney, E. 2008. Velvet: Algorithms for de novo short read assembly using de Bruijn graphs. Genome Res. 18:821-9.

Zipfel, C. 2008. Pattern-recognition receptors in plant innate immunity. Curr. Opin. Immunol. 20:10-16.

\section{AUTHOR-RECOMMENDED INTERNET RESOURCES}

PtoT1 genome website: genome.ppws.vt.edu/pseudomonas Pseudomonas-Plant Interaction website: pseudomonas-syringae.org Newbler assembler: www.454.com 